\title{
Gastric cancer associated structure in mucus glycoproteins shown as a clinically useful marker
}

\author{
I Häkkinen, T Nevalainen, R Paasivuo, P Partanen, K Seppälä, P Sipponen
}

\begin{abstract}
A new monoclonal antibody has been developed which is capable of detecting structures in gastric mucus glycoproteins expressed in the fetus and in adult gastric mucosa in conditions such as gastric carcinoma. Cancer associated monoclonal antibodies were selected by testing them against various mucous glycoprotein samples from the alimentary tract, including salivary glycoproteins from both secretory and nonsecretory subjects, and cancerous and normal gastric juice glycoproteins. They were tested against 1000 samples of gastric juice from an unselected population. Immunochemical characterisation suggested that the glycoproteins picked up by $P_{4}$ and $i_{11}$ include one of the compounds reacting with rabbit anti-fetal sulphoglycoprotein antigen serum. On the basis of a clinical trial and immunohistological evaluation further evidence was obtained of $\mathbf{P}_{\mathbf{4}}$ as the most promising antibody for further experimentation. A total of $\mathbf{3 0 2}$ gastric juice specimens from patients with various gastric symptoms were analysed using the enzyme linked immunosorbent assay technique and $\mathbf{P}_{4}$ antibody. Of 10 gastric cancers, nine had $P_{4}$ in the gastric juice. A positive correlation was found between gastric ulcer and the appearance of $\mathbf{P}_{4}$. Duodenal ulcers were not correlated to $P_{4}$. Atrophic gastritis and $P_{4}$ coincided less frequently. Raised $\mathbf{P}_{\mathbf{4}}$ values were found in between $3 \%$ and $9 \%$ of subjects, depending on the population. Cancer cases showed high $\mathbf{P}_{4}$ values, which allows adjustment of the lower limit of a positive result to high level whereby a considerable number of non-cancerous $\mathbf{P}_{4}$ positives are omitted.
\end{abstract}

Department of Pathology, University of Turku, Department of Gastroenterology, Medical Clinic, University of Helsinki, Department of Pathology, Jorvi Hospital, Espoo, and Labsystems Research Laboratories, Helsinki, Finland

I Häkkinen

T Nevalainen

R Paasivuo

P Partanen

K Seppälä

P Sipponen

Correspondence to:

Dr I Häkkinen, Department of

Pathology, University of

Turku, Kinnamyllynk 8-10, 20520 Turku, Finland.

Accepted for publication 3 December 1990
Gastric cancer cells and their precursors, being of epithelial origin, have characteristics of epithelial mucous cells such as the capacity to secrete mucus glycoproteins. Consequently, we find these secretory products in the gastric juice. Earlier studies on fetal sulphoglycoprotein antigen (FSA), where a rabbit antiserum was used to detect qualitatively these gastric cancer associated blood group type glycoproteins, were based on this idea. ${ }^{2}$ It was stated that the antibodies detected structures other than known blood group determinants in these blood group type glycoproteins. ${ }^{3}$ Immunohistological data suggested that FSA structures were expressed in normal ontogenic fetal development of the gut. ${ }^{4}$

Detection of the FSA for the diagnosis of gastric cancer among rural populations with a high incidence of gastric cancer was promising in the early 1970s but became less important later, with a decline in incidence of this geographically associated type of cancer. More precisely, although the method was satisfactory in showing early cases of cancer, the FSA test was plagued by a high rate of non-cancerous FSA positives, about $8 \%$ in an unselected population.

In experimental studies gastric carcinomas can be produced by administration of a carcinogen. ${ }^{6}$ When the dose of the carcinogen was reduced a stage was found where the fetal glycoprotein markers were expressed but a morphological cancer did not develop. ' A relatively short exposure to carcinogens, such as chemicals in our surroundings, may cause an analogous situation, and thus explain the recently observed tendency in our population towards an increase in non-cancerous FSA positives.

The FSA glycoprotein, characterised by polyclonal rabbit antiserum, necessarily contains a multitude of determinants which in individual samples can be present in incomplete combinations. The possibility exists that some of the FSA determinants are more strongly cancer associated - that is, expressions triggered later in carcinogenesis. To investigate this, monoclonal antibodies were produced, then characterised and selected for use in a clinical trial. The present study gives immunochemical and histoimmunological data on the most promising of these monoclonal antibodies, $\mathbf{P}_{4}$. A clinical study using $\mathrm{P}_{4}$ was included to support our concept of its association with cancer.

\section{Methods}

PREPARATION OF GLYCOPROTEIN ANTIGENS FOR IMMUNISATION

The cancerous gastric juice sample was taken from a patient with gastric cancer (age 67 years, blood group $\mathrm{O}+$, histological type: diffuse carcinoma). The specimen was taken by oral tube after an overnight fast, the patient having received $100 \mathrm{ml}$ of phosphate buffered saline $\mathrm{pH}$ 6.5 . The antigen was prepared following the procedure described earlier. ${ }^{8}$ Polyanions from the gastric juice were separated using cetyl pyridinium chloride (CPC) (Merck, Germany) and ethanol precipitations. The supernatant of the CPC precipitation containing the neutral glycoproteins was further treated with four volumes of ethanol, and the precipitate was dissolved in saline, to be used in immunisation as fraction 1. CPC precipitated polyanions were divided into two fractions by a further CPC-salt precipitation procedure, and they were used in immunisations as fractions 2 and 3.

PRODUCTION OF MONOCLONAL ANTIBODIES Preparation of monoclonal cell fusions and the 
cloning procedure was as described elsewhere. ${ }^{9}$ To measure the specific reactivity of the mouse antibodies to the antigen, the enzyme linked immunoassay technique was used, with antimouse immunoglobulin conjugated with alkaline phosphatase. The antigenic preparation used in immunisations was coated in microplate wells by treatment with $0.2 \%$ glutaraldehyde in $0.1 \mathrm{~mol} / 1$ phosphate buffer $\mathrm{pH} 5$, at $+4^{\circ} \mathrm{C}$ overnight. ${ }^{10}$

The quantitative assay for FSA using the monoclonal antibodies produced was developed by detecting the antigen on the solid phase with the monoclonal antibody. Attempts to coat native gastric juice samples met with difficulties. This was probably caused by competition for the fixing sites by too many kinds of unrelated proteins. Half an hour's incubation at $65^{\circ} \mathrm{C}$ in $0.1 \%$ papain-cysteine solution buffered in 0.2 $\mathrm{mol} / \mathrm{l}$ acetate to $\mathrm{pH} 5.6$ split most of the proteins and solubilised the FSA antigen molecules without destroying the antigenic properties. Four volumes of ethanol added subsequently precipitated the glycoproteins, which in aqueous solution could then be coated onto the solid phase.

\section{TESTS FOR SPECIFICITY OF THE CLONES}

The specificity of clones was tested by measuring their reactivity with (i) non-secretory saliva, (ii) secretory saliva, (iii) 10 samples of gastric juice from normal control subjects, (iv) 10 samples of cancerous gastric juice, and (v) blood group $\mathrm{ABH}$, Lewis ${ }^{\mathrm{ab}}$ systems, performed as in routine blood group serology. In addition, selected antibodies were further used to test 1000 specimens of gastric juice from an unselected population aged 49-74 years which had been preserved frozen from an earlier study.

Selected specific monoclonal antibodies were immobilised using $\mathrm{CNBr}_{2}$ activated Sepharose (Pharmacia-LKB Biotechnology, Uppsala, Sweden). A small antibody column was prepared for affinity purification of the glycoprotein antigen. Gas chromatography for sugar analysis of the affinity purified glycoprotein was performed at the Department of Medical Chemistry, University of Helsinki. A gel filtration profile of the glycoproteins in various preparations was obtained on a Sephacryl S-200 column, detected by the specific monoclonal antibody.

Sodium dodecylsulphate-polyacrylamide gel electrophoresis ${ }^{11}$ was performed using $6 \%$ or $8 \%$ vertical slab gels either under reducing or nonreducing conditions. For immunoblotting, ${ }^{12}$ the polypeptides were transferred onto nitrocellulose sheets (Trans-Blot Transfer Medium, Bio-RAD, Richmond, CA). Immunoblotting was performed and detected by using peroxidase coupled antimouse immunoglobulins (Dakopatts, Glostrup, Denmark).

\section{IMMUNOHISTOLOGICAL STUDY}

The immunochemically selected monoclonal antibody $\mathrm{P}_{\mathbf{4}}$ (see Results) was tested. A standard immunoperoxidase procedure was used on formaldehyde fixed tissue sections. Parallel negative controls were included in all assays. The following organs and conditions were studied: non-cancerous stomach, gastric carcinoma, pancreatic carcinoma, small intestine, normal colon, colonic carcinoma, gall bladder, and submandibular and parotid glands.

\section{CLINICAL STUDY}

The clinical study included 302 patients referred for gastroscopy at the gastroenterology unit of the University Hospital, Medical Department, Helsinki. The cases were deliberately not selected in any respect, the aim being to get an overall picture of specimens from the different groups of patients. To standardise the gastric juice specimens each patient drank $100 \mathrm{ml}$ of $0 \cdot 1$ $\mathrm{mol} / \mathrm{l}$ phosphate buffered saline $\mathrm{pH} 6.5$ immediately before the gastroscope was introduced. The stomach was then emptied by suction through the gastroscope. The samples were preserved in sealed tubes at $-20^{\circ} \mathrm{C}$.

$\mathrm{P}_{4}$ analysis was performed using the enzyme linked immunosorbent assay (ELISA) technique, the papain treated samples being coated onto solid phase as described above. Since in the preliminary tests $i_{11}$ (see Results) gave negative results in some of the cancer cases, $\mathrm{P}_{4}$ was selected as the more promising antibody, and patient analyses are reported for $\mathrm{P}_{4}$ only. To control the daily variation in the ELISA results, a standard antigen prepared from a $\mathrm{P}_{4}$ positive sample was included in every run. The results are given as absorbance figures. The lower limit of a positive result was set at 0.40 absorbance, nearly the cut off of the background value.

\section{Results}

All three antigen preparations caused an immune response in mice. Cloning of the fusions gave 20 active clones in fusion 1 (antigen preparation 1), 23 in fusion 2 , and 18 in fusion 3 . The tests performed are listed in Table I. Two individual clones, $i_{11}$ in fusion 1 and $P_{4}$ in fusion 3 , were selected to be the most promising as regards their cancer association. Unlike $i_{11}$ and $P_{4}$, most of the other clones reacted to salivary and normal gastric glycoproteins. The two selected clones were further tested against 1000 specimens of gastric juice derived from an unselected rural population. $\mathrm{P}_{4}$ antibody gave a positive reaction in 30 samples, whereas $i_{11}$ reacted in only 14 of the same $30 \mathrm{P}_{4}$-positive samples. All $i_{11}$ positive samples were also $\mathrm{P}_{4}$ positive.

Affinity purified glycoprotein from a $\mathrm{P}_{4}$ anti-

TABLE I Tests for characterisation of the most promising monoclonal antibodies, $P_{4}$ (from immunisation with acid cancerous gastric glycoproteins) and $i_{11}$ (from immunisation with neutral cancerous gastric glycoproteins)

\begin{tabular}{lcc}
\hline Tests performed & $P_{4}$ & $i_{11}$ \\
\hline $\begin{array}{l}\text { Enzyme linked immunoassay technique: } \\
\text { Reactivity with non-secretory saliva }\end{array}$ & - & - \\
$\begin{array}{l}\text { Reactivity with secretory saliva } \\
\text { Reactivity with } 10 \text { cancerous gastric juice } \\
\text { samples }\end{array}$ & - & - \\
$\begin{array}{l}\text { Reactivity with } 10 \text { non-cancerous gastric } \\
\text { juice samples }\end{array}$ & $10 / 10$ & $10 / 10$ \\
$\begin{array}{l}\text { Reactivity with 1000 samples from } \\
\text { unselected population (aged 49-74 years) }\end{array}$ & - & - \\
$\begin{array}{l}\text { Reactivity with blood group antigens: } \\
\text { ABH } \\
\text { Lewis }\end{array}$ & - & - \\
\hline
\end{tabular}


TABLE II Gas chromatography analysis of sugars of $P_{4}$ affinity-purified cancerous gastric glycoprotein

\begin{tabular}{ll}
\hline & Percentage \\
\hline Mannose & $18 \cdot 7$ \\
Galactose & $38 \cdot 8$ \\
Fucose & $11 \cdot 7$ \\
Glucosamine & $20 \cdot 1$ \\
Sialic acid & $3 \cdot 7$ \\
Galactosamine & 14.9 \\
\hline
\end{tabular}

body column indicated that besides the $\mathrm{P}_{4}$ epitope, the $i_{11}$ epitope could also be situated in the same macromolecule, but the picture varied from one sample to another so that macromolecules with $\mathrm{P}_{4}$ epitopes but not $\mathrm{i}_{11}$ appeared. On the other hand, $i_{11}$ alone without the $P_{4}$ epitope was not found. In the clinical study, $i_{11}$ was lacking in some of the $\mathrm{P}_{4}$ positive cancer cases. On these grounds, $\mathrm{P}_{4}$ was considered to associate with a maximum number of the cancer-associated glycoproteins.

Table II gives the results of sugar analyses of the $\mathrm{P}_{4}$ antibody affinity purified glycoprotein. A similar preparation from a subject with blood group A gave a positive reaction with monoclonal anti- $\mathrm{A}$, indicating that $\mathrm{P}_{4}$ positive macromolecules contain a blood group determinant. This is consistent with earlier studies on FSA. ${ }^{3}$ Rabbit anti-FSA also reacted with $\mathrm{P}_{4}$ immunopurified FSA in immunodiffusion. $\mathrm{P}_{4}$ reacted with samples of meconium.

Figure 1 shows the gel filtration profile of a $\mathrm{P}_{4}$ positive sample of gastric juice glycoprotein, both untreated and after papain treatment. No appreciable alteration in the molecular size of the $\mathrm{P}_{4}$ molecules can be observed. The profile indicates some polydispersity of the $\mathrm{P}_{4}$ active macromolecules, the molecular size ranging from 40000 to 150000 . It further suggests that the papain treatment solubilises some other glycoproteins.

The immunoplotting pattern of a $P_{4}-i_{11}$ positive sample after sodium dodecylsulphatepolyacrylamide gel electrophoresis is given in Figure 2. Compared with the profile from the Sephacryl S-200 run (Fig 1), no discrepancy exists since $6 \%$ electrophoresis gel apparently obstructs the free movement of the largest molecules. Figure 3 shows the standard dilution curve of the $\mathrm{P}_{4}$ antibody enzyme linked immunoassay, the papain treated antigen on the solid phase.

Immunohistologically, $\mathbf{P}_{4}$ was localised in gastric cancer cells in the cytoplasm and in the secretion (Fig 4A). In none of the sections did all cancer cells show the $\mathrm{P}_{4}$ structure. The staining picture varied also in its intensity. As a rule the

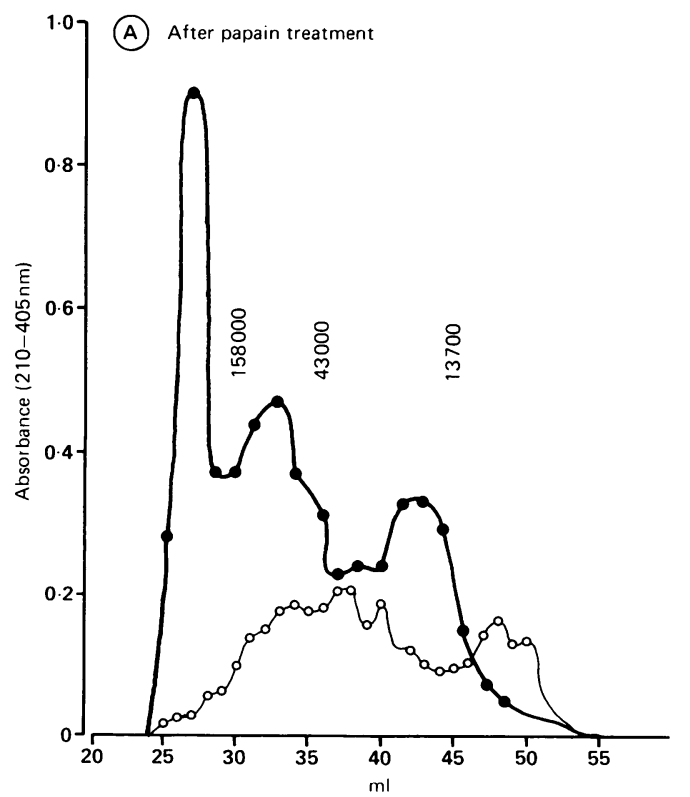

Figure 1: Gel filtration on Sephacryl S-200 of a pooled sample of gastric juice mucus glycoproteins. (A) After treatment with papain; $(B)$ no enzymatic treatment. Detection at $210 \mathrm{~nm}(\mathbf{O})$ detection at $405 \mathrm{~nm}$ with $P$ monoclonal antibody using enzyme immunoassay $(\bigcirc)$.

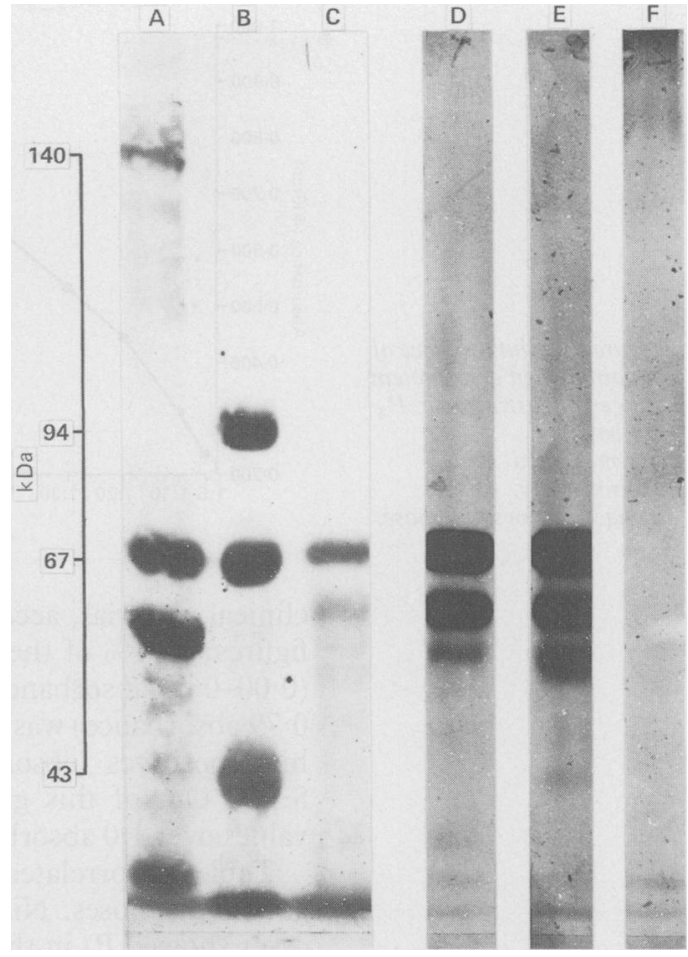

Figure 2: Immunoblotting pattern of a $P_{4}-i_{11}$ positive sample after sodium dodecylsulphate-polyacrylamide gel electrophoresis. Lines $A$ and B: molecular size standards; line $C$ : protein staining; line $D: P_{4}$ antibody; line $E: i_{11}$ antibody; line $F$ : an unrelated monoclonal antibody.

normal gastric mucosa of the same section - that is, adjacent to a tumour - was negative as was the mucosa from non-cancerous stomachs. Immunohistologically, metaplasia and atrophic gastritis were always negative, both in the gastric cancer cases and in non-cancerous cases. Exceptionally, some single glands stained positively (Fig 4B), less frequently in non-cancerous stomachs than in cancer cases. Some dysplastic glands adjacent to a cancer were positively stained in about two thirds of the cases (Fig 4C). Table III summarises the immunohistological results for various gastrointestinal materials.

Table IV gives the results of the $\mathrm{P}_{4}$ analysis of

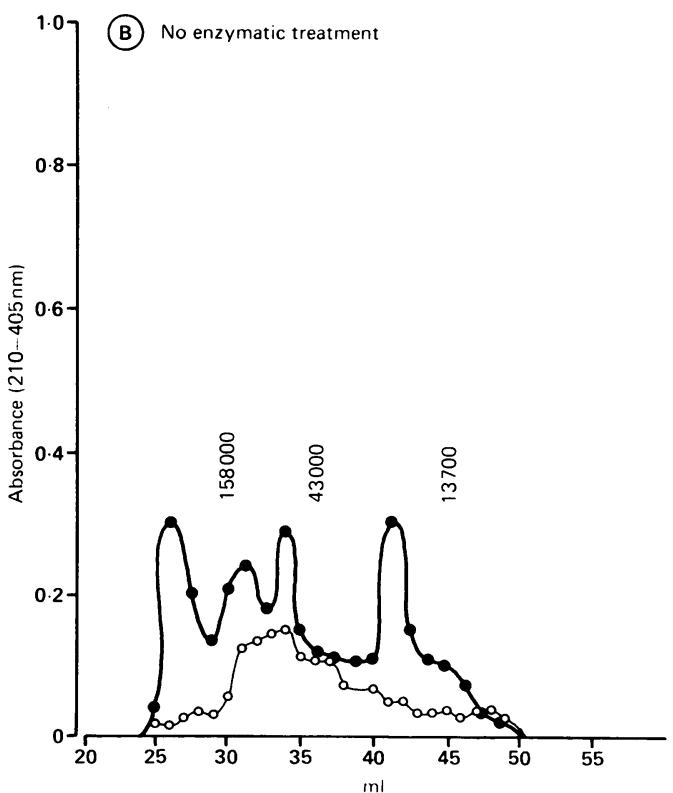


Figure 3: Dilution curve of papain treated glycoprotein antigen of gastric juice. $P_{4}$ antibody

enzyme linked

immunoassay.

Antigen on the solid phase.

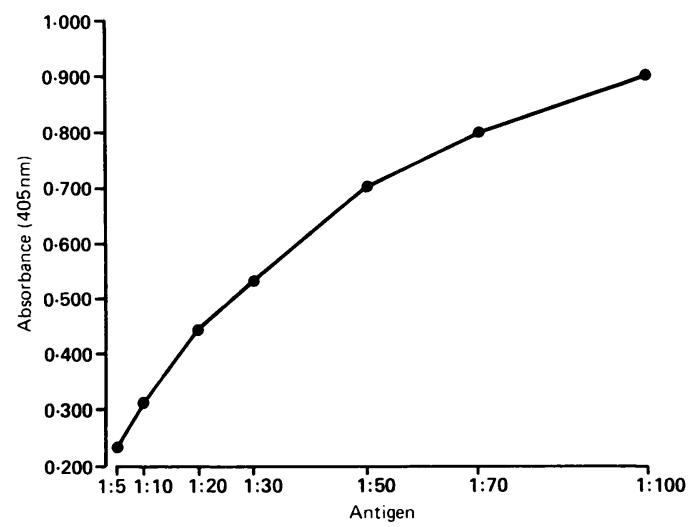

clinical material, according to their absorbance figures; $83 \cdot 1 \%$ of the samples were $\mathrm{P}_{4}$ negative $(0.00-0.39$ absorbance). Slight elevation $(0.40$ 0.79 absorbance) was found in $7 \cdot 9 \%$. The rate of high positives (absorbance 0.80 or over) was $\mathbf{8 . 9 \%}$. Out of this group, a subgroup of high values over 1.0 absorbance is shown separately.

Table $\mathrm{V}$ correlates the $\mathrm{P}_{4}$ results to clinical gastric diagnoses. Nine of the 10 gastric cancer cases showed $\mathrm{P}_{4}$ in the gastric juice. Only six of the 30 cases of atrophic gastritis were $P_{4}$ positive. Among benign gastric disorders, peptic ulcer was definitely associated with $\mathbf{P}_{4}$. On the other

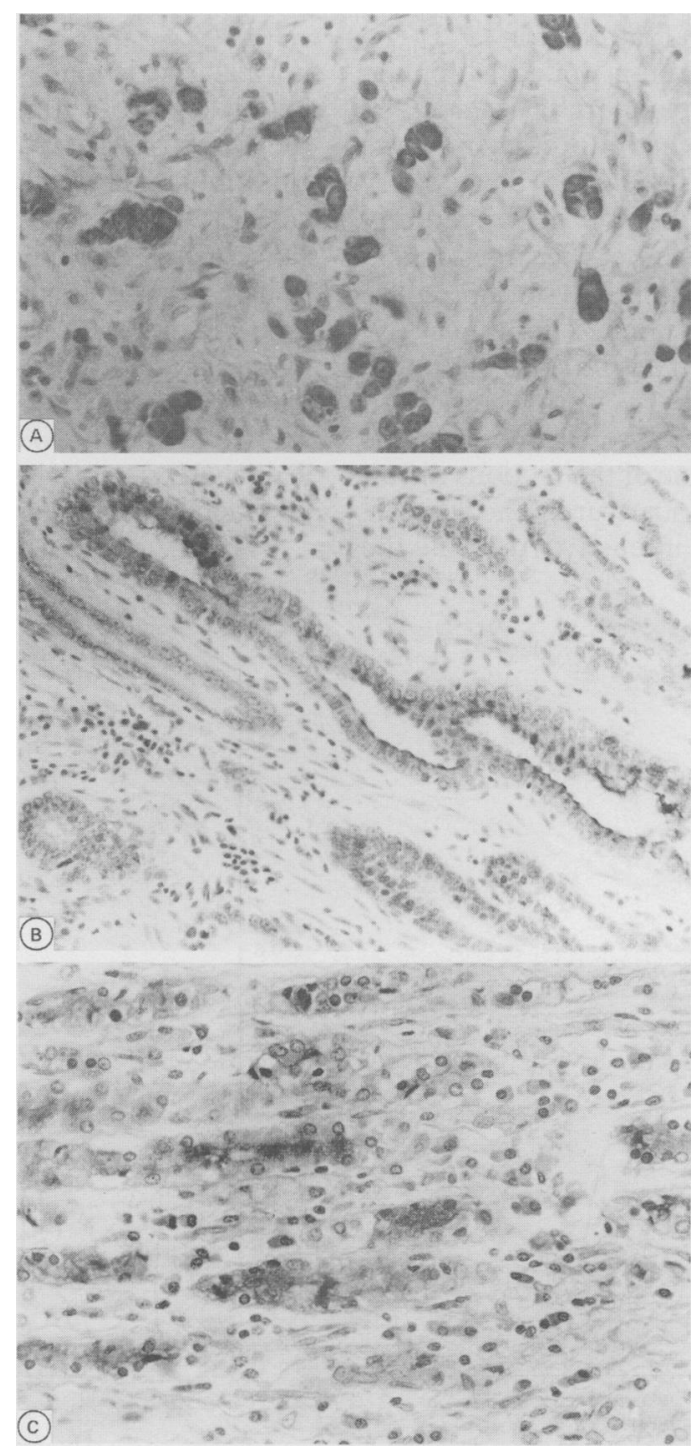

hand, $\mathrm{P}_{4}$ and duodenal ulcer showed no positive correlation.

\section{Discussion}

All active clones reacted with the glycoprotein structures. Immunisation with a restricted selection of glycoproteins possibly leaves more reactive capacity in mouse in the immune system to identify different components compared with immunisation where whole cancer cells are used. ${ }^{13}$

Monoclonal antibodies $\mathrm{P}_{4}$ and $\mathrm{i}_{11}$ were selected using reactions to glycoproteins of the upper alimentary canal. A positive reaction to all 10 samples of cancerous gastric juice and a negative reaction to controls (Table I) was a promising result. Among 1000 gastric juice specimens collected earlier, 30 were positive to $P_{4}$ and 14 to $i_{11}$. These incidence rates only illustrate the rate of marker-positive samples in an unselected population of high cancer risk age groups. In the absence of clinical data no correlation to cancerous or precancerous states can be made from them.

$P_{4}$ and $i_{11}$ reacted with meconium, which indicates that the antigen structures belong to normal fetal development, unlike the mutation based aberrations such as blood group A-like structures. ${ }^{1+15}$ Blood group specificity was absent, which points to the assumption that other antigen structures are involved in $\mathrm{P}_{4}-\mathrm{i}_{11}$ expressions in the blood group-like gastric glycoproteins of FSA. The $\mathrm{P}_{4}$ immunopurified glycoprotein reacted in immunodiffusion with the polyclonal anti-FSA, thus connecting the $\mathbf{P}_{4}$ glycoprotein to the FSA.$^{8}$ However, it is not yet clear whether true $\mathrm{P}_{4}$ specificity is also present in rabbit anti-FSA.

Immunohistologically $\quad \mathbf{P}_{4}-\mathrm{i}_{11} \quad$ antibodies detected only structures of gastric origin among all alimentary organs and diseases studied. Our clinical data indicate that non-cancerous $P_{4}-i_{11}$ production also exists, although it is not easy to show this immunohistologically.

$\mathrm{P}_{4}$ analysis from gastric juice seems to detect $80 \%$ to $90 \%$ of gastric carcinomas. In this study the cancer cases were not selected but were from a group of gastroenterology patients and in various clinical states. Whereas the rate of $P_{4}$ positivity in the unselected population was about $3 \%$, both low and high positives included, the rate in selected cases from a gastroenterology unit would be expected to be higher. It actually varied between $9 \%$ and $16 \%$, depending on how high the lower limit of a positive test was set. Gastric carcinomas gave high values of $\mathrm{P}_{4}$, which allows a rise of the lower limit of positivity, and consequently the cutting off of an appreciable number of non-malignant $\mathrm{P}_{4}$ positives. A larger group of cancer patients is, however, needed to fix this limit definitely. For instance, raising the limit from 0.40 to 0.80 in our series cuts off one cancer case but at the same time 23 noncancerous $\mathrm{P}_{4}$ positive cases.

In our cases gastric ulcer showed the highest rate of non-cancerous $\mathrm{P}_{4}$ positivity. On the other hand, atrophic gastritis, which is known to be associated with gastric cancer, showed less frequent correlation to $\mathrm{P}_{4}$ positivity. In addition, we 
TABLE III Material studied immunohistologically using the $P_{4}$ antibody

\begin{tabular}{lccc}
\hline Specimen & $\begin{array}{l}\text { No of } \\
\text { specimens }\end{array}$ & Immunohistological findings & $P_{4}$ \\
\hline Non-cancerous stomach & 5 & $\begin{array}{l}\text { 1 of 5 cases: single positive glands } \\
\text { 4 or 5 cases: totally negative }\end{array}$ & + \\
Gastric carcinoma & & 14 of 22 cases: part of cancer cells positive & + \\
& 22 & 16 of 22 cases: a few positive dysplastic glands & + \\
Pancreatic carcinoma & 2 & 3 of 22 cases: totally negative & - \\
Small intestine & 2 & & - \\
Normal colon & 10 & & - \\
Colonic carcinoma & 10 & & - \\
Gall bladder & 4 & & - \\
Submandibular gland & 2 & & - \\
Parotid gland & 2 & & \\
\hline
\end{tabular}

$\star 12$ were of intestinal and 10 of diffuse type.

TABLE IV Results of $P$ analyses grouped by absorbance figures

\begin{tabular}{lc}
\hline Absorbance & $P_{4}$ \\
\hline $0 \cdot 00-0 \cdot 39$ & $251(83 \cdot 1 \%)$ \\
$0 \cdot 40-0 \cdot 79$ & $24(7 \cdot 9 \%)$ \\
$0 \cdot 80+$ & $27(8 \cdot 9 \%)$ \\
$1 \cdot 00+$ & $18(6 \cdot 0 \%)^{\star}$ \\
Total & 302
\end{tabular}

^Included in the $0 \cdot 80$ column. found no immunohistological verification of $\mathrm{P}_{4}$ being localised in atrophic gastritis. In fact there was a $\mathrm{P}_{4}$ positive rate of about $10 \%$ in acute gastritis (Table V). It thus seems plausible that the origin of biochemical alteration is to be found outside a morphological atrophic gastritis. Some benign conditions, gastric ulcer, and to a less extent gastritis apparently can include parallel factors, being linked to carcinogenesis at the biochemical level. The positive results associated with benign gastric ulcer and gastritis could limit its use as a marker for gastric cancer.

Gastric emptying is a routine part of gastroscopy, and sampling gastric juice only requires a minute to remove the yield to a preserving container. However, to guarantee a proper specimen for quantitative $\mathbf{P}_{4}$ analysis, it is essential that the buffer is swallowed. By natural contraction movements it will properly mix.

Patients' attitudes to gastric examination depend greatly on motivation. The inconvenience caused by gastroscopy is widely accepted, thanks to the availability of information on its superior accuracy. In the 1970s, acceptance of gastric intubation in our population study of 40000 patients was $75 \% .^{5}$ We have to bear in mind that at present there is no serum marker which is capable of detecting gastric malignancy reasonably early. A gastric juice marker has a far better potential for this. In mass screening or clinics, $\mathrm{P}_{4}$ could be considered as a signal of the existence of a dysplastic condition or a malignancy.

Supported by a grant from the Finnish Cancer Society.
TABLE V $P_{4}$ measurements from gastric juice using the ELISA technique and correlated to clinical diagnoses

\begin{tabular}{lcccc}
\hline \multicolumn{5}{c}{ Absorbance } \\
\cline { 2 - 5 } Diagnosis & $0 \cdot 0-$ & $0 \cdot 40-$ & & \\
\hline Acute gastritis & $0 \cdot 39$ & $0 \cdot 79$ & $0 \cdot 8+$ & $1 \cdot 0+$ * \\
Atrophic gastritis & 75 & 5 & 3 & 3 \\
Erosion & 30 & 2 & 4 & 1 \\
Gastric ulcer & 6 & 4 & 0 & 0 \\
Duodenal ulcer & 15 & 5 & 6 & 4 \\
Hyperplastic polyp & 17 & 1 & 0 & 0 \\
Gastric carcinoma & 5 & 3 & 1 & 1 \\
Oesophageal carcinoma & 1 & 1 & 8 & 7 \\
Gastric lymphoma & 0 & 0 & 1 & 1 \\
Diagnosis total & 149 & 0 & 1 & 1 \\
No disorder verified & 102 & 3 & 24 & 18 \\
Total & 251 & 24 & 3 & 0 \\
& & & 27 & 18 \\
\hline
\end{tabular}

*Included in the $0 \cdot 80+$ column.

1 Häkkinen I. An immunochemical method for detecting carcinomatous secretion from human gastric juice. Scand carcinomatous secretion from
Gastroenterol 1966; 1: 28-32.

2 Häkkinen I, Viikari S. Occurrence of fetal sulphoglycoprotein antigen in the gastric juice of patients with gastric diseases. Ann Surg 1969; 169: 277-81.

3 Häkkinen IPT. Gastric fetal sulfoglycoprotein antigen (FSA and blood group antigens A and B. Int Arch Allergy 1974; 47: $380-7$.

4 Häkkinen I, Korhonen LK, Saxén L. The time of appearance and distribution of sulphoglycoprotein antigens in the human foetal alimentary canal. Int $\mathcal{f}$ Cancer 1968; 3: 582-92.

5 Häkkinen IPT, Heinonen R, Inberg MV, Järvi O, Vaajalahti $\mathrm{P}$, Viikari S. Clinicopathological study of gastric cancers and pre-cancerous states detected by fetal sulfoglycoprotein pre-cancerous states detected by fetal sulfogl
antigen screening. Cancer Res $1980 ; 40: 4308-12$.

6 Sasajima K, Kawachi T, Sano T, Sugimura T, Shimosato Y, Shirota A. Esophageal and gastric cancers with metastases induced in dogs by $\mathrm{N}$-ethyl-N-nitro-N nitrosoguanidine. f Natl Cancer Inst 1977; 58: 1789-94.

7 Häkkinen IPT, Heinonen R, Isberg U, Järvi O. Canine gastric glycoprotein antigens in early carcinogenesis. Cancer 1984; 53: $928-34$.

8 Häkkinen IPT. The purification procedure for human gastric juice FSA and its chemical composition. Clin Exp Immunol 1980; 42: 57-62.

9 Köhler G, Milstein C. Derivation of specific antibody producing tissue culture and tumor lines by cell fusion. Eur $\mathcal{F}$ Immol 1976; 6: 511-9.

10 Holt PG, Cameron KJ, Stewart GA, Sedgwick J, Turner K. Enumeration of human immunoglobulin-secreting cells by the ELISA-plague method: IgE and IgG isotypes. Clin Immunol Immunopathol 1984; 30: 159-64.

11 Laemmli UK. Cleavage of structural proteins during the assembly of the head of bacteriophage T4. Nature $1970 ; 227$ 680-3.

12 Towbin H, Staehelin T, Gordon J. Electrophoretic transfer of proteins from polyacrylamide gels to nitrocellulose sheets: procedure and some applications. Proc Natl Acad Sci USA procedure and so

13 Eisen HN, Siskind GW. Variations in affinities of antibodies during the immune response. Biochemistry 1964; 3: 996 during.

14 Häkkinen I. A-like blood group antigen in gastric cancer cells of patients in blood groups O or B. F Natl Cancer Inst 1970; 44: 1183-93.

15 Hirohashi S, Clausen H, Yamada T, Shimosato Y, Hakomori $\mathrm{S}$. Blood group A cross-reacting epitope defined by monoclonal antibodies NCC-LU-35 and -81 expressed in cancer of blood group $\mathrm{O}$ or $\mathrm{B}$ individuals: its identification as $\mathrm{Tn}$ antigen. Proc Natl Acad Sci USA 1985; 82: 7039-43. 